\title{
An experimental study of the driving of a solenoid type diesel common rail injector using microprocessors
}

\author{
Jung Guk Kim¹, Choong Hoon Lee ${ }^{2 *}$ \\ ${ }^{1}$ Department of Automotive Engineering, Graduate School of Industry, \\ ${ }^{2}$ Department of Mechanical and Automotive Engineering \\ Seoul National University of Science and Technology, 232 Kongneungro, Nowon-kuSeoul, Korea 139-743 \\ ${ }^{2 *}$ corresponding author, chlee5@seoultech.ac.kr
}

\begin{abstract}
A fuel injection system to drive a common rail injector was developed using an 8-bit microprocessor. Common rail pressure control and injector driving systems are both essential for injecting fuel at a controlled pressure. With various duty ratios of the square wave generated from the CCP (capture compare PWM) pin of a microprocessor to the common rail pressure controller, the common rail pressure can be controlled continuously. An increase of the duty ratio of the supplied PWM square wave decreases the common rail pressure. The common rail pressure is controlled at 600, 1000, and 1500 bars. Moreover, a solenoid-type common rail injector driver was developed using a microprocessor. In order to drive the common rail injector, the current in the solenoid should be controlled using what is known as a peak and hold pattern, which consists of a high current level with a short time duration (peak) in the first step and a low current level with a long time duration (hold) in the subsequent step. The CCP pin in the microprocessor was used to generate the peak and hold current pattern. The PWM square wave generated from the CCP pin has a duty ratio of $100 \%$ of the PWM square wave for the peak current, with ratios of $10 \%, 20 \%$, and $30 \%$ for the hold pattern. The developed common rail pressure controller and injector driver were applied to an injection rate measurement system. The needle lift in the common rail injector was also determined by attaching an accelerometer to the nozzle holder.
\end{abstract}

Keyword-common rail, pressure controller, injector driver, microprocessor, fuel injection timing

\section{INTRODUCTION}

Recent attention directed towards energy resources and protection of the environment has led to increased interest in diesel engines. Direct-injection diesel engines, which use an electronically controlled common rail system, have appreciably improved in terms of their thermal efficiency [1-5]. In a diesel engine with a mechanical fuel injection system, fuel injection pressures vary with the engine speed and the fuel line pressure varies from 0 to 700 bar over one engine cycle. In addition, accurate control of the fuel injection timing and quantity as required by multiple injections is very difficult to achieve with a mechanical fuel injection system [6-7]. On the other hand, a common rail fuel injection system, which utilizes electronic control, is capable of increasing the injection pressure, and allows for flexible injection timing and accurate control of the injection quantity and injection pattern as a function of the engine speed and torque. Direct-injection diesel engines with a mechanical fuel injection system are associated with the issues of excessive emission of smoke, noise and vibration. Recent diesel engine performance levels have been enhanced because the common rail injector is actuated by a solenoid, making it possible for the injector to control the injection timing and quantity precisely without restrictions. Moreover, multiple injections, which are difficult with mechanical fuel injection systems, are possible with exact injection timing and quantity levels. In general, establishing a common rail fuel injection system in a laboratory to measure the fuel injection rate under various experimental conditions, such as single injection, pilot injection and multiple injection settings, requires expensive equipment [8]. Previous studies of common rail injector drivers and pressure controllers are insufficient and/or did not show enough detail in their circuit diagrams to construct an injector driver and pressure controller [9-10]. In this study, 8-bit microprocessors were used to develop a common rail injector driver and common rail pressure controller for laboratory experiment. The Microchip ${ }^{\circledR}$ 8-bit microprocessor (model 16F917) [11] was used in this study. In addition, 3N3055, MJ11016 and FET IRP150 transistors were used for switching the high current and voltage source to drive the common rail pressure controller and injector driver. The developed common rail pressure controller and injector driver in this study were applied to a Bosch injection rate measurement system [12-13]. The Bosch injection rate measurement method is based on recording the pressure waves within measuring and following tubes. The pressure wave is caused by an injection of fuel into a tube containing a compressible fluid. This principle is based on the pressure-velocity equation valid for a single pressure wave in a quasi-stationary flow. Also, the needle lifting timing, which is very important with regard to the performance of a diesel engine, was determined by measuring the impact signal of an accelerometer mounted outside of the nozzle holder. 


\section{COMMON RAIL PRESSURE CONTROLLER}

Common rail diesel engine performance capabilities are improved by injecting fuel into a combustion chamber with an electronically controlled injector at very high pressure levels which are maintained constantly independent of the engine operating conditions. The injected fuel quantity from the common rail injector can be calculated precisely with the injection duration and rail pressure compared to a mechanical fuel injection system, whose injection pressure varies continuously during the fuel injection process.

A rail pressure sensor is mounted onto the common rail to measure the rail pressure. A constant rail pressure can be obtained by controlling the pressure control valve in the common rail. Fig. 1 shows the developed common rail pressure controller circuit with the included microprocessor. A potentiometer depicts the common rail sensor signal. The potentiometer voltage is read by the analog input pin RA0 of the microprocessor (PIC16F917). The duty ratio PWM square wave which corresponds to the read potentiometer voltage is output to the CCP pin (RD2) in the microprocessor. The duty-ratio-controlled PWM square wave is supplied to cascaded Q1 (2SC1815), Q2 (2SA1015), and Q3 (2N3055) transistors, which switch the pressure controller driver source at $12 \mathrm{~V}$, resulting in an amplification of the PWM square wave voltage of the RD2 pin. The amplified PWM square wave (the check point signal) is supplied to the common rail pressure controller. Fig. 2 shows the amplified PWM square wave voltages as measured with an oscilloscope. Fig. 2a, Fig. 2b, and Fig. 2c present the amplified PWM square wave voltages corresponding to 1500, 1000, and 600 bars, respectively. The controlled rail pressure deceases as the duty ratio of the PWM square wave increases.

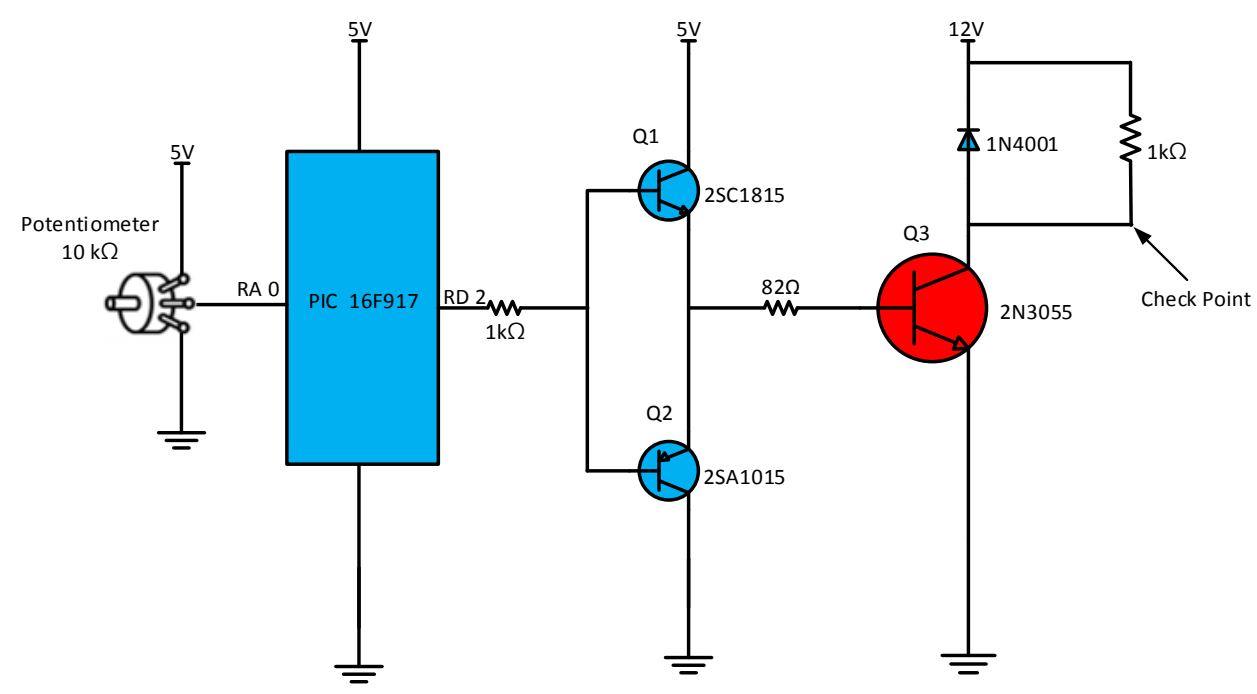

Fig. 1Common rail pressure controller circuit

\section{SOLENOID TYPE COMMON RAIL INJECTOR DRIVER}

In general, solenoid-type common rail injectors are driven by controlling the current supplied to the injector via the peak and hold method. In order to shape the current flow for this method, the $80 \mathrm{~V}$ source supplied to the injector in this case should be switched on/off while varying the duty ratio of the PWM square wave. The peak current corresponds to a duty ratio of $100 \%$, while the hold current applies when the duty ratio is less than $100 \%$, such as $10 \%, 20 \%$, or $30 \%$.Fig. 3 shows the common rail injector driver circuit, which consists of a microprocessor, a transistor, and a diode. The total fuel injection duration is $1 \mathrm{~ms}$, which consists of a peak time of $100 \mu \mathrm{s}$ and a hold time of $900 \mu \mathrm{s}$. The microprocessor outputs the PWM square wave to generate the peak and hold current through the CCP pin (RD2). The PWM square wave voltage from the CCP pin RD2 is the TTL level. By combining the Q1 (2SC1815), Q2 (2SA1015), and Q3 (MJ11016) transistors, the PWM square wave from the CCP pin RD2 is amplified to a high voltage/current level (80V/20A: maximum current). For an experiment involving a single injection, the common rail injector driver shown in Fig. 3 does not show a thermal load problem in the MJ11016 transistor, however, for the repeated fuel injection case, the MJ1106 transistor burns out. In order to overcome the thermal load problem during repeated injections, the MJ11016 transistor was replaced with the 2N3055 and FET IRF150N transistors. Fig. 4 shows a common rail injector driver circuit with the 2N3055 and FET IRF150N components. The circuit in Fig. 4 does not show evidence of the thermal load problem up to a repeated injection frequency of $15 \mathrm{~Hz}$.Figs. 5-7 show the measurement results of the injector driving voltage, the PWM square wave voltage of the CCP pin and the injector driving current with the injector driver created with the driver circuit shown in Fig. 3. All of the experimental conditions in Figs. 5-7 are identical, except for the duty ratio of the hold square wave. That is, the total injection duration is $1 \mathrm{~ms}$, which consists of a $500 \mu$ s peak time with a $100 \%$ duty ratio square wave and a $500 \mu$ s hold time with a $30 \%$ (Fig. 5), $40 \%$ (Fig. 6), and 50\% (Fig. 7) duty ratio square wave. The measurement was performed with an ECU scanner. 
Figs. 5b-7b show the measured voltage of the PWM square wave from the CCP pin RD2 when driving the injector with the peak and hold method; the peak signals show nearly identical shapes, while the hold waves appear differently due to the different duty ratio used.
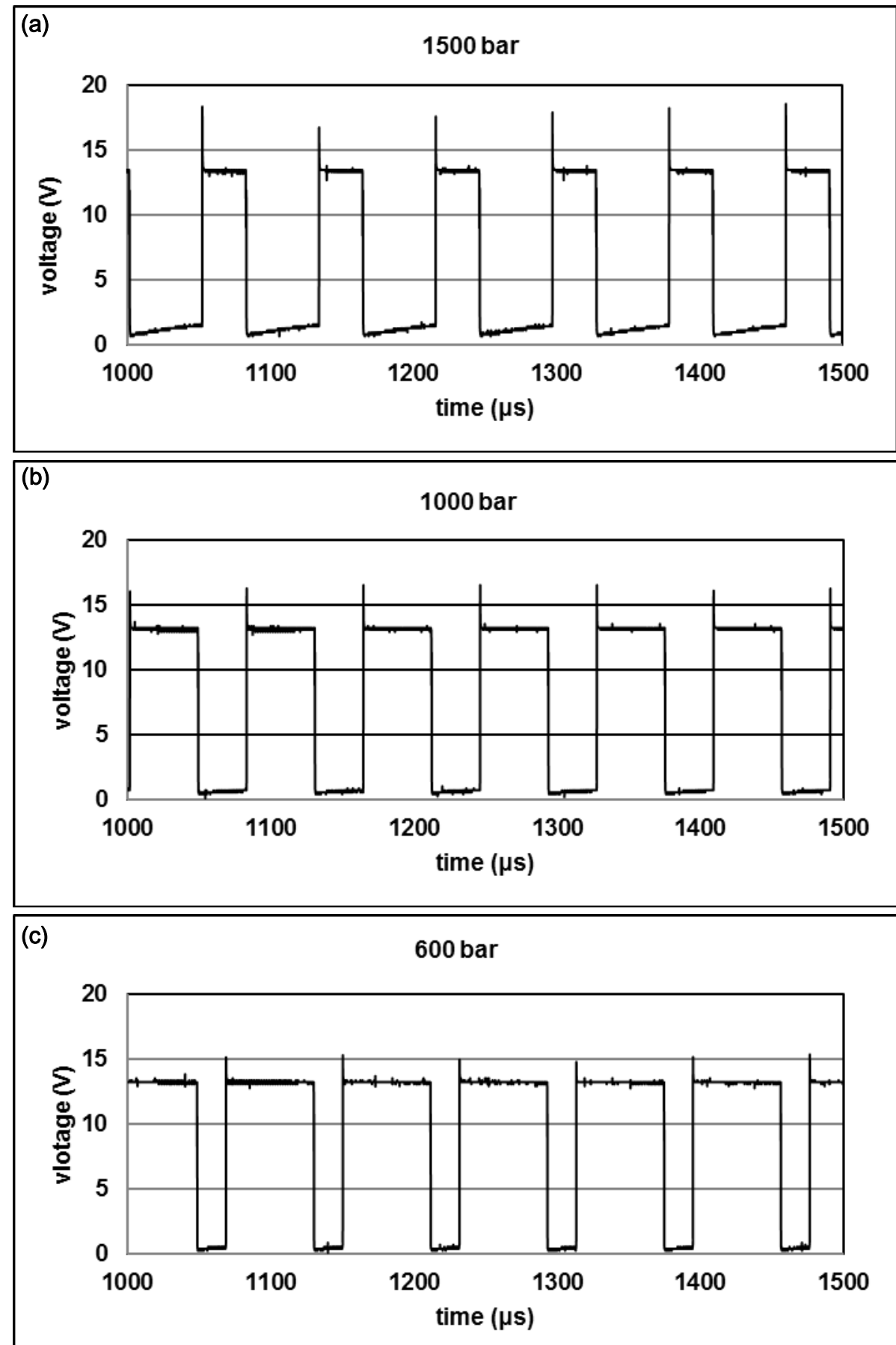

Fig. 2Voltages (measured at the check point) of the amplified PWM square waves according to the controlled common rail pressure: (a) 1500 bar, (b) 1000 bar, and (c) 600 bar 


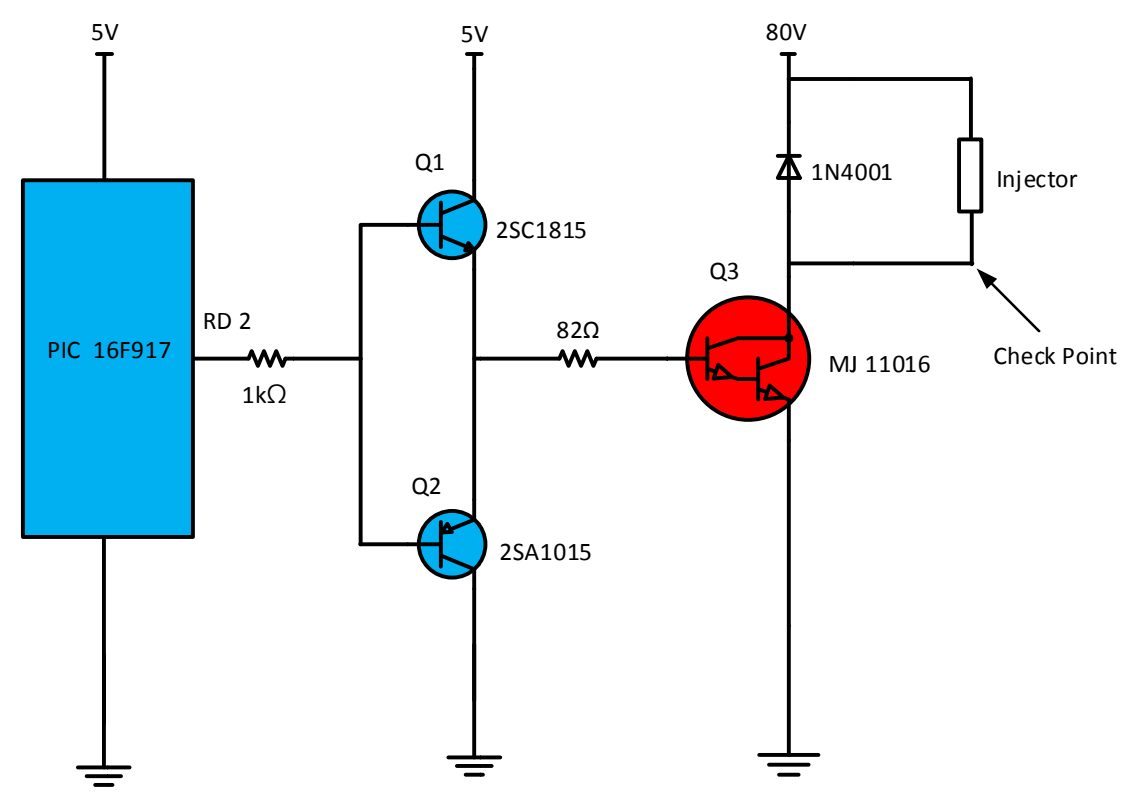

Fig. 3 Common rail injector driver circuit for generating the injector driving voltage of a peak and hold PWM square wave with a MJ11016 transistor

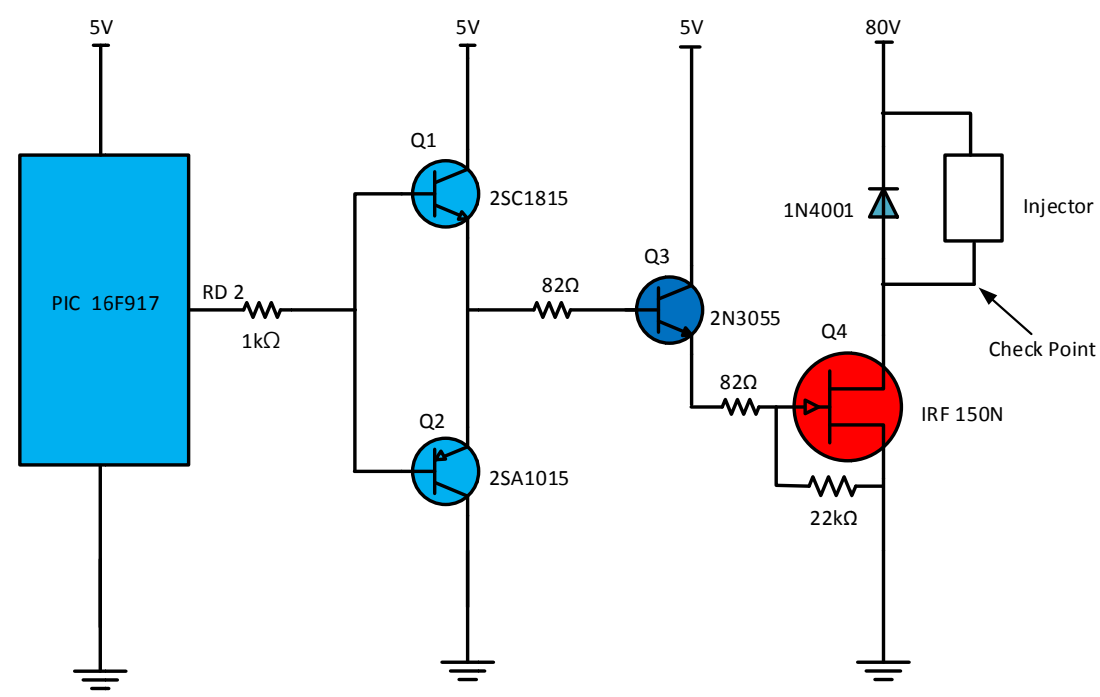

Fig. 4Common rail injector driver circuit for generating the injector driving voltage of a peak and hold PWM square wave with FET IRF150N device

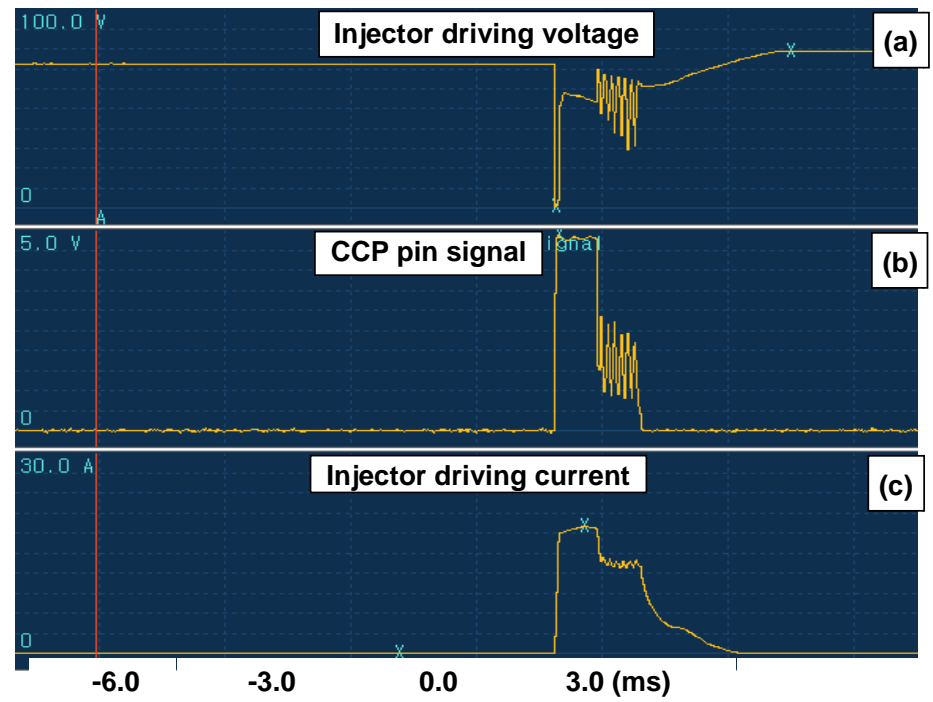

Fig. 5(a) injector driving voltage, (b) CCP pin signal, and (c) injector driving current (30\% duty ratio) 


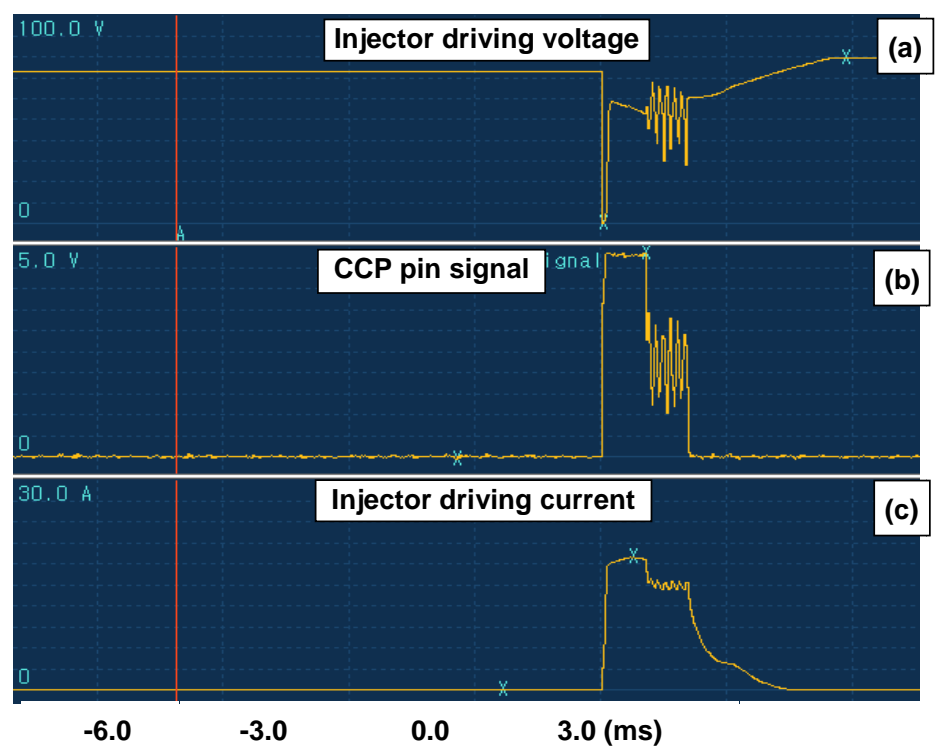

Fig. 6(a) injector driving voltage, (b) CCP pin signal, and (c) injector driving current (40\% duty ratio)

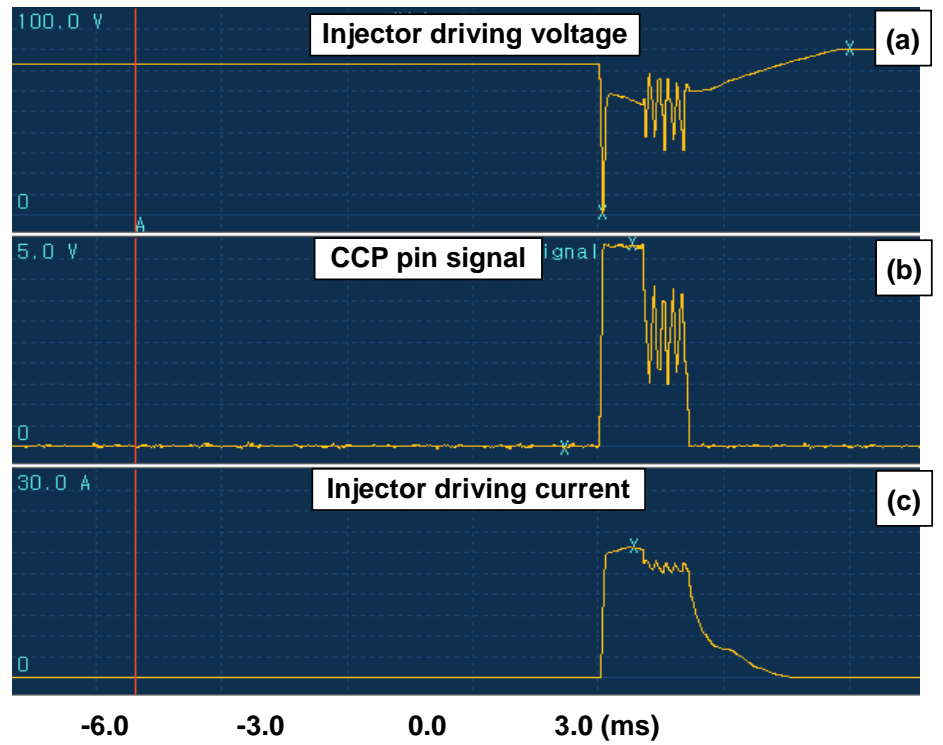

Fig. 7(a) injector driving voltage, (b) CCP pin signal, and (c) injector driving current (50\% duty ratio)

Figs. 5a-7a show the injector driving voltages which are amplified by the Q1 (2SC1815), Q2 (2SA1015), and Q3 (MJ11016) transistors for the CCP pin PWM square wave. The injector driving waves in Figs. 5a-7a are synchronized with the CCP pin PWM square wave in Figs. 5b-7b, respectively. Figs. 5c-7c depict the injector driving currents which flow through the solenoid in the injector when the injector is driven with the injector driving voltage in Figs. 5a-7a. The peak current in Figs. 5a-7a is approximately 19A. The hold currents differ depending on the controlled duty ratio of the PWM hold waves in each case. The hold currents corresponding to Fig. 5a, Fig. 6a and Fig. 7a are 13.5A, 15A, and 16A, respectively. As the duty ratio of the hold square wave increases, the hold current in the injector increases. Thus, the hold current was effectively controlled by varying the duty ratio of the PWM hold wave.

\section{APPLICATION OF THE DEVELOPED SYSTEM TO BOSCH INJECTION RATE MEASUREMENT SYSTEM}

The shape of the fuel injection rate has a great effect on the performance of a diesel engine. Specifically, the shape of the injection rate is essential in CFD simulations involving an internal combustion engine. In order to measure the rate of fuel injection of the common rail injector, the BOSCH-type rate of an injection flow bench [14] was used in this study. The principle of the Bosch injection rate measurement method is based on measuring the pressure waves during a fuel injection event. The pressure wave is caused by the fuel injection 
event, which here is an injection into a length of tube which is filled with a compressible fluid, typically diesel fuel.

The entire experimental system shown in Fig. 8 consists of a high-pressure pump driven by a 7 kW AC motor, a common rail and an injector, and the Bosch injection rate measurement system. Diesel fuel sucked by a lowpressure pump passes through a fuel cooler and a fuel filter and is then pressurized up to 1500 bar by a highpressure pump. The common rail injector injects the highly pressurized fuel with the injector driver developed in this study. The Bosch injection rate measurement system consists of a piezoelectric pressure sensor, a charge amplifier, a measurement tube, a throttle valve, a scale and an oscilloscope. Additionally, an accelerometer was attached outside of the injector holder to record all instances of needle movements. The experimental process for measuring the injection rate and recording needle movements can be summarized as follows. An AC motor, which is directly connected to a high-pressure fuel pump, is rotated at a constant velocity, which pressurizes the common rail at a constant pressure through adjustments of the potentiometer knob. The common rail fuel pressure leading to the injector is then monitored by the pressure sensor while being manipulated to reach the target pressure. As the common rail pressure reaches the target pressure and is then maintained at the target pressure, the injector driving voltage supplied to the injector is switched on/off by the peak and hold method. Considering the measurement results in Figs. 5-7, the fuel injection pressure and injection duration used in this study are 1500 bar and $1 \mathrm{~ms}$, respectively. The fuel injection duration of $1 \mathrm{~ms}$ consists of a peak time of $100 \mu \mathrm{s}$ and a hold time of $900 \mu \mathrm{s}$. The duty ratios of the peak and hold square waves are $100 \%$ and $10 \%$, respectively.

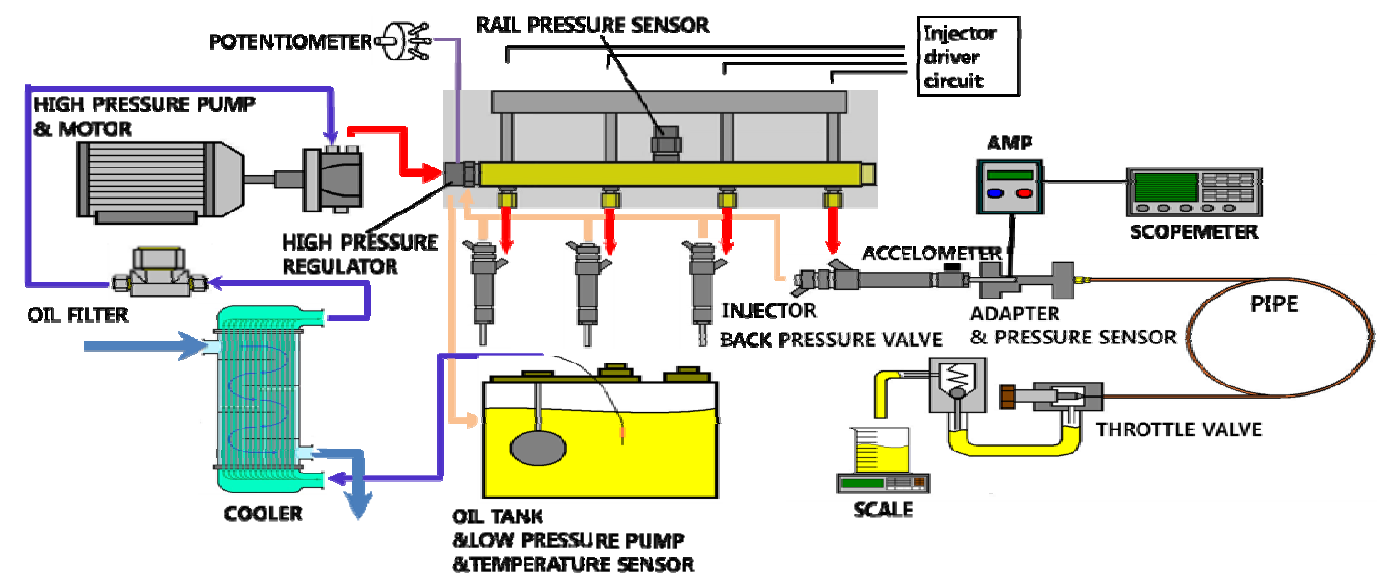

Fig. 8Experimental setup used to measure the fuel injection rate and needle movement

The piezoelectric pressure sensor, accelerometer, PWM wave and injector driving voltage are recorded with a four-channel digital oscilloscope during the fuel injection event. These measurement results are shown in Fig. 9. The voltage measurement result of the PWM square wave from the CCP pin is shown in Fig. 9a. The PWM square wave from the CCP pin is a clear square wave. Fig. $9 \mathrm{~b}$ shows the injector driving voltage supplied to the common rail injector. The injector driving voltage is comparatively well synchronized with the PWM square 

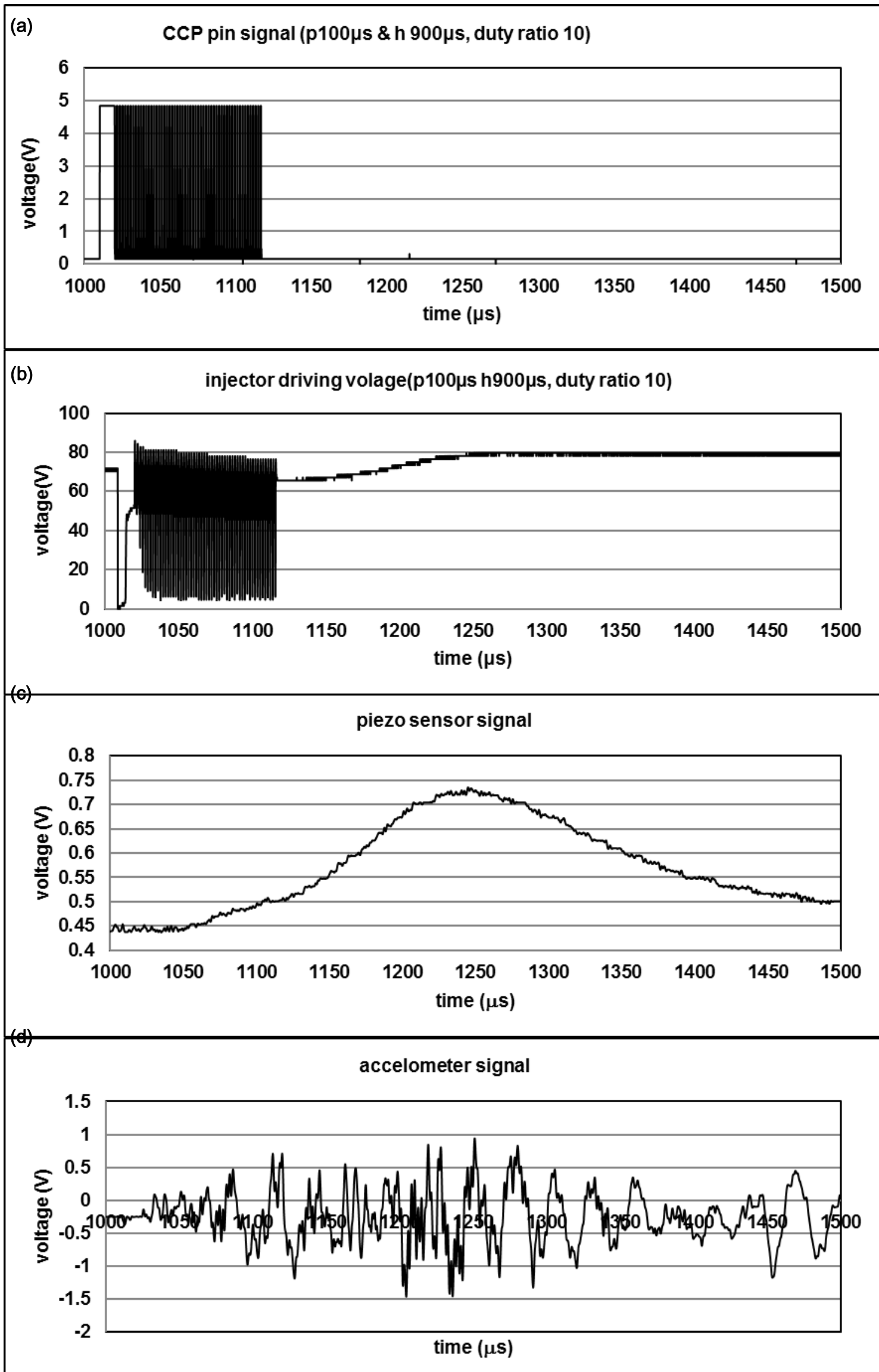

Fig. 9 Measurement results with the Bosch injection rate method and accelerometer for a 1ms single injection: (a) CCP pin signal, (b) injector driving voltage, (c) piezo-sensor signal, and (d) accelerometer signal 

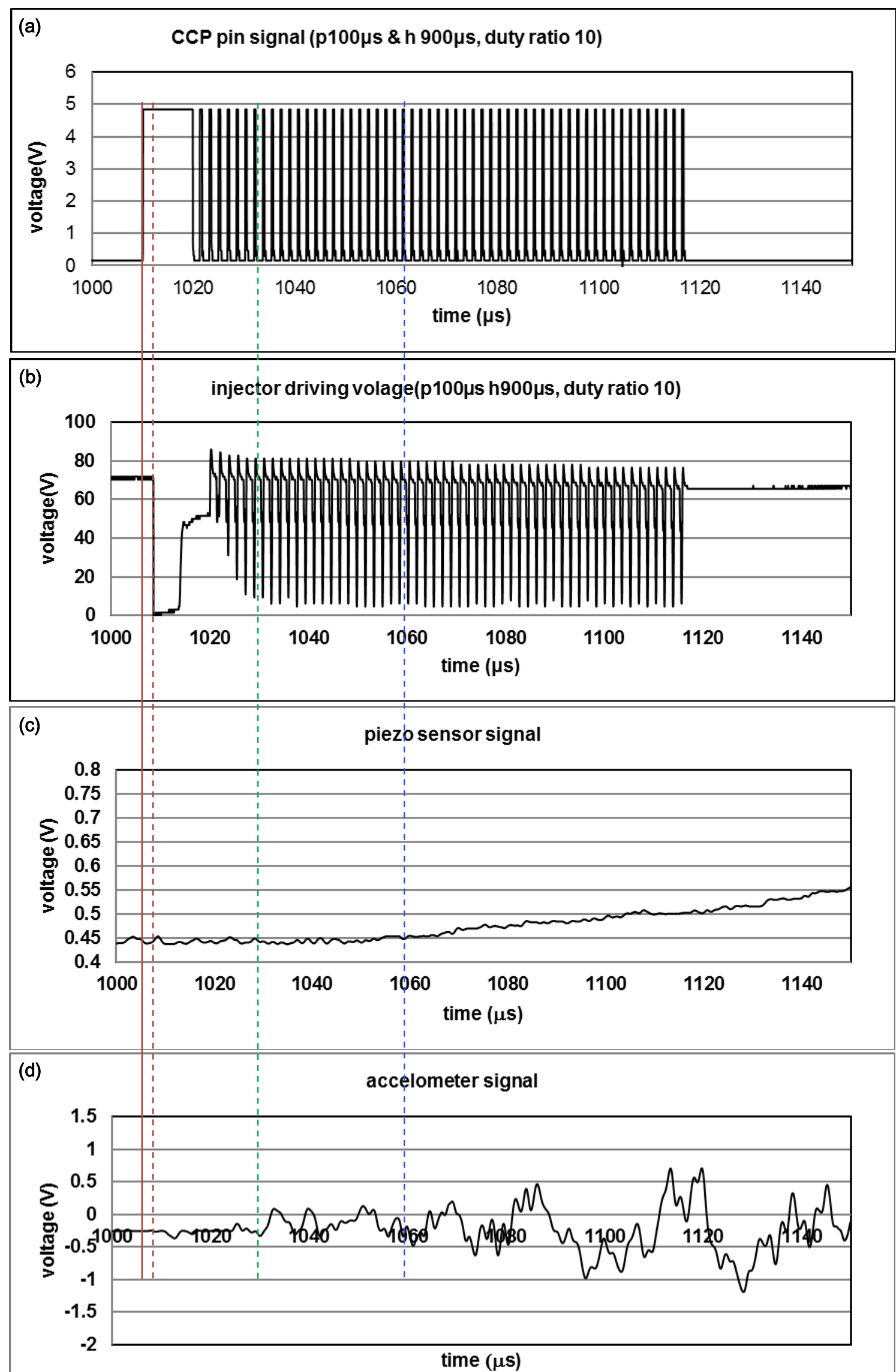

Fig. 10 Magnification of the results in Fig. 9 in the measurement time range of 1000-1150 $\mu$ s: (a) CCP pin signal, (b) injector driving voltage, (c) piezo-sensor signal, and (d) accelerometer signal 
wave from the CCP pin. Fig. 9c shows the pressure wave signal caused by the fuel injection event upon the injection into a length of tube as measured by the piezo-electric pressure sensor. The piezo-electric sensor voltage starts to increase somewhat later, after the CCP pin peak wave starts to rise. The piezo-electric sensor voltage increases continuously after the CCP pin hold wave time. Fig. 9d shows the voltage of the accelerometer sensor attached onto the outside of the injector holder to record the timing of needle movements. Fig. 9d shows that the accelerometer can effectively determine the instant the needle starts to move but cannot catch the return of the needle. Fig. 10 shows magnified images of the results of Fig. 9 in the measured time range of 1000-1150 $\mu$ s. The solid line denotes the reference line of the rising edge (refer to Fig. 10a) of the peak wave from the CCP pin. The starting time of the injector driving signal, which is displayed in Fig. 10b as the falling edge (the red dashed line) is delayed by $2 \mu$ s relative to the reference solid line. The accelerometer sensor signal shown in Fig. $10 \mathrm{~d}$ detects the shock wave caused by the movement of the needle at the timing indicated by the green dashed line. The needle moves $22 \mu \mathrm{s}$ after the start of the rising edge of the peak wave. The fuel injection time from the nozzle exit can be identified from the piezo-electric sensor signal shown in Fig. 10c. The piezo-sensor signal starts to increase at a time of $1057 \mu$ s, as displayed by the blue dashed line. The actual fuel injection is delayed by $25 \mu$ s after the needle moves because the injected fuel takes time to pass through the nozzle hole passage. In summary, fuel injection occurs at a time of approximately $47 \mu$ s after the rising edge of the CCP pin peak wave.

\section{Conclusion}

The common rail pressure controller and injector driver investigated in this study were developed using 8-bit microprocessors, transistors and FET devices. The developed common rail pressure controller and injector driver were applied to a Bosch injection rate measurement system. Additionally, the needle movement and actual fuel exit timing from the nozzle hole were measured. The following conclusions can be drawn after an analysis of the results.

1. As the duty ratio of the PWM square wave supplied to the common rail controller decreases, the common rail pressure increases and changes continuously with the rotation of the potentiometer knob. The common rail pressure controller using a microprocessor successfully controls the common rail pressure.

2. The common rail injector driver using a microprocessor effectively controls the current via the peak and hold pattern, and the solenoid-type common rail injector injects high-pressure fuel successfully with the developed common rail injector driver.

3. The detailed fuel injection process of the common rail injector using the Bosch injection rate measurement method and accelerometer was investigated and the fuel injection timing from the nozzle exit was delayed with the following four steps from the rising edge of the CCP pin peak wave: the rising edge of the CCP pin peak wave, the falling edge of the injector driving signal, the instant of the needle movement, and the fuel passing through nozzle hole passage.

\section{ACKNOWLEDGMENT}

This study was supported by the Research Program funded by the Seoul National University of Science and Technology.

\section{REFERENCES}

[1] J. B. Heywood, Internal Combustion Engine Fundamentals, McGraw-Hil, (1989), 491-566.

[2] T. Kamimotoand H. Kobayashi H., “Combustion Process in Diesel Engine,” Prog.Energy Combust. Sci., vol. 17, pp. 163-189, 1991.

[3] M. Ikegami,“Problems of Diesel Engine Combustion,” Combust. Sci. and Tech. (Japan), vol. 3, pp. 151-157, 1996.

[4] T. Kamimoto and H. Kobayashi, “Combustion Process in Diesel Engine,” Prog.Energy Combust. Sci., vol. 17,163-189, 1991.

[5] M. Ikegami, "Problems of Diesel Engine Combustion,” Combust. Sci. and Tech. (Japan), vol. 3, pp. 151-157, 1996.

[6] A. J. Schuster, H. Langer, and G. Loose, “The Regenerable Trap Oxidizer-An Emission Control Technique for Diesel Engines,” SAE paperNo. 850015, 1985.

[7] H. Guodong, "New Strategy on Diesel Combustion Devolpment,” SAE paper No. 900442, 1990.

[8] NI Driven, http://www.ni.com/pdf/manuals/375969a.pdf.

[9] K. R. Cho, “Development of Injector Controller,” Korea Institute of Information and Communication Engineering, vol. 8, No. 2, pp. 279-284, 2013.

[10] B. G. Oh, S. S. Oh, K. Y. Lee and M. H. Sunwoo, “Development of an Injector Driver for PiezoActuated Common Rail Injectors," SAE Paper 2007-01-3537, 2007.

[11] PIC16F917 datasheet, http://ww1.microchip.com/downloads/en/DeviceDoc/41250E.pdf

[12] W. Bosch, "The fuel rate indicator: A new measuring instrument for display of the characteristics of individual injection,” SAE paper No. 660746, 1966.

[13] P. J. Tennison et al.“An Experimental and Numerical Study ofSprays from a Common Rail InjectionSystem for Use in an HSDI Diesel Engine,” SAE paper No. 980810, 1998

[14] C. H. Lee, "Measuring the needle lift and return timingof a CRDI injector using an accelerometer,"International Journal of Engineering and Technology, vol. 6. No. 5, pp. 2482-2487, 2014. 